Bioelectrochentistry and Bioenergetics 7 (1980) $125-155$

J. Electroanal. Chem. 116 (1980) $125-155$

Elsevier Sequoia S.A., Lausanne - Printed in Italy

\title{
306 - Nucleotides and Related Substances: Conformation in Solution and at Solution ! Electrode Interfaces *
}

\author{
by William T. Bresnahan, Jacques Moirouxo, Zdenek Samecoo \\ and Philip J. Elving \\ Derpartment of Chemistry, The University of Mrichigan, Ann Arbor, Michigan, \\ 48rog. U.S.A.
}

Revised manuscript received December zand 1979

Summary

The problems involved in inferring conformation and orientation from electrochemical measurements are considered as are the implications of extrapolating the results for relatively simple nucleotides to biopolymers. The determination of conformation, e.g., shape in solution - more particularly, when approaching the electrode - largely depends on estimation of the effective molecular cross-section as reflected in the experimentally measured diffusion coefficient, $D$; for example, formation of associated species as in base stacking is usually reflected in a variation in $D$ and, often, in redox potential. The determination of conformation at the solution/electrode interface is often intimately connected with the state and orientation of an adsorbed species - more particularly of its electroactive and adsorption sites - relative to the electrode surface. Current trends in inferring such interfacial conformation for DNA and derived large nucleic acid species are summarized; the adsorption pattern seen on oxidation of $\mathrm{NADH}$ at carbon electrodes is reviewed.

\section{Introduction}

The extensive investigation in recent years bv electrochemical measurements of the behavior of large entities derived from DNA and RNA,

* Invited lecture at the $5^{\text {th }}$ International Symposium on Bioelectrochemistry. 3-8 September 1969. Weimar (D.D.R.).

- Permanent address : Ecole Normale Supérieure de l’Enseignement Technique, 94230 Cachan, France

oo Permanent address : J. Heyrovsky Institute of Physical Chemistry and Electrochemistry, I ro oo Prague I, Czechoslovalia.

$0302-4958 / 80 / 0125-0155$ Clsevier Sequoia 
has produced apparently conflicting interpretations of the causes of such behavior as related to the conformation of these entities when in solution, when approaching the aqueous solution/mercury electrode interface, and when at the interface.

While the present authors, who have avoided involving themselves with species more complex than a dinucleotide or a relatively short oligomer, have found the results and interpretations of work on large species published by various groups e.g., those at Brno, Jena and Jülich, to be of great interest, they do not consider that, at present, they could define and appraise the contemporary situation in respect to the conformation of the nucleic acid polyelectrolytes in solution and at the interface to the satisfaction of all of the different groups involved. Consequently, the present paper only indicates some of the viewpoints expressed regarding large nucleic acid species, summarizes some of the principal concepts and $:-$ iumptions involved in obtaining information on the conformation of $3 . \ldots$-ler nucleotides in solution and at interfaces, e.g., in regard to adsorption and electron transfer, and notes the resulting implications for more complex species.

Space limitations force a rather didactic presentation; the reader should refer to the original references for supporting evidence and logical relationship development. No attempt has been made to assign priority for the various findings and explanations reported; similarly, no attempt at thoroughness of coverage has been attempted.

\section{Conformation in solution}

The primary information obtainable in respect to conformation in solution - at the least, when approaching the solution/electrode interface - would seem to be the effective cross-sectional area as inferred from the apparent diffusion coefficient determined by polarographic diffusion current or related measurements, e.g., classical use of electrical conductivity- A secondary source would be the variation of the halfwave or related potential, e.g. $U_{i}$ or $U_{c}^{0}$, with concentration of the electroactive species. Thus, association in solution to produce a larger species, could shift $U_{t=}$ in two or more ways, e.g., as the result of a chemical reaction preceding electron transfer,

$$
\text { "stacked" base } \rightleftharpoons \text { "free" base } \stackrel{\text { "re- }}{\longrightarrow} \text { reduced base }
$$

Stacking of bases, which would alter the electron density in the base, affecting $U_{y}$ in much the same manner as substituents on an aromatic ring, would be effective in direct reduction of stacked bases.

\section{Deduction of shape ist solution}

The extent to which the effective shape of an electroactive species in solution varies, for example, from a planar slab to a more or less sym- 
metrical sphere, can be approximated by comparing the experimentally determined diffusion coefficient, $D$, which corresponds to the effectively minimum cross-section, with the diffusion coefficient of a spherical particle in solution at infinite dilution, $D_{0}$, as calculated by the STokEsErNSTEIx equation:

$$
D_{0}=\frac{k}{V_{m}^{1 / 3}} \mathrm{~cm}^{2} \sec ^{-1}
$$

where $V_{n}$ is the apparent molecular volume (molecular weight/density) of the solid compound and $k$ is $3-32 \times 10^{-5}$ for aqueous solution at $25^{\circ} \mathrm{C}$. The limiting diffusion current constant, $I_{d}$, at zero concentration, $I_{a}$, can be calculated from the ILKovic equation using $D_{0}$ as $D$ :

$$
I_{d}=607 n D^{1 / 2}
$$

Experimental $D$ values can be calculated by equation 3 from $I_{d}$ based on the average diffusion-controlled limiting current $I_{d}$ :

$$
I_{d}=\frac{\boldsymbol{I}_{d}}{\operatorname{cnt}^{2 / 3} t^{1 / 6}}
$$

Fxtended forms of the Irkovic equation can be used in equations 3 and 4 as necessary.

Experimental $I_{d}$ values for an adenine nucleoside-nucleotide series (Table I), being 1.7 to 2 times calculated $I_{0}$ values, produce $D$ values which are $2 . S$ to 4 times calculated $D_{0}$ values, $[x] i . e$. , the effective barrier to diffusional mass transport is a fraction of that expected for a spherical molecule. This can be rationalized on the basis of the preferred ainti conformation of the nucleosides and nucleotides in solution, which results in a relatively planar molecule. Consequently, the average orientation of the diffusing species is with the purine ring plane perpendicular to the interface and the protonated reduction site facing the electrode: the effective barrier to diffusion is the cross-section areal bulk of the planai purine moiety plus those portions of the ribose or ribosophosphate moieties which protrude from the purine ring plane. The fact that the experimental $D$ for ATP deviates least from the calculated $D_{0}$, indicates a conformation closest to spherical, e.g., a folded structure due to the two terminal dissociated phosphate groups being able to approach the protonated $N(I)$ and amino groups to form a closely packed zwitter-ion.

The previous argument involving equations 2 to + can, of course, be reversed. Experimental $D_{0}$ values, based on extrapolating $\boldsymbol{I}_{d}$ data to zero concentration, can be used to estimate effective molecular volume, from whose magnitude information might be obtained regarding such solution phenomena as solvation sphere magnitude, intra- and intermolecular association, and molecular conformation and orientation. It may also be possible to deduce molecular volumes of solution species from the effective areas covered by the molecule when adsorbed at the interface (cf. subsequent discussion of such areas). 
Table I. Variation of diffusion parameters for an adenine nucleotide sequence.

\begin{tabular}{|c|c|c|c|c|c|}
\hline \multirow{2}{*}{ Compound } & \multicolumn{2}{|c|}{ Experimental } & \multicolumn{2}{|l|}{ Calculated } & \multirow{2}{*}{$\boldsymbol{I}_{d} / \boldsymbol{I}_{\mathrm{o}}$} \\
\hline & $I_{d}^{a}$ & $\begin{array}{c}D^{b} \\
10^{5} \mathrm{~cm}^{2} \sec ^{-1}\end{array}$ & $\begin{array}{c}D_{0}^{e} \\
10^{5} \mathrm{~cm}^{2} \sec ^{-1}\end{array}$ & $I_{0}^{d}$ & \\
\hline
\end{tabular}

$\begin{array}{llllll}\text { Adenine } & 8.5 & 1.23 & 0.35 & 4.5 & 1.89 \\ \text { Adenosine } & 7.5 & 0.95 & 0.29 & 4.1 & 1.83 \\ \text { Deoxyadenosine } & 7.9 & 1.06 & 0.29 & 4.2 & 1.88 \\ \text { AMP } & 7.9 & 1.06 & 0.27 & +.0 & \text { r.98 } \\ \text { d.MIP } & \mathbf{S . 0} & 1.08 & 0.27 & 4.0 & 2.00 \\ \text { ADP } & 7.3 & 0.90 & 0.26 & 3-9 & \text {..87 } \\ \text { ATP } & 6.4 & 0.69 & 0.24 & 3.8 & 1.68\end{array}$

a Calculated from $I_{d}$ by equation + and extrapolated to zero concentration.

- Calculated from $I_{d}$ by equation 3 .

c Calculated from the molecular volume by equation 2 .

d Calculated from $D_{0}$ by equation 3 .

Table 2. Variation of diffusion coefficients for a cytosine nucleotide sequence $a$.

\begin{tabular}{llccc}
\hline & & \multicolumn{2}{c}{ Limiting Current } \\
\cline { 3 - 5 } Compound & \multicolumn{2}{c}{$\begin{array}{c}\text { Temp. } \\
\text { coeff. }\end{array}$} & $\begin{array}{c}\text { Activation } \\
\text { energy }\end{array}$ \\
\cline { 2 - 5 } & $25^{\circ}$ & $0^{\circ}$ & $\% /^{\circ} \mathrm{C}$ & kcal/MLole \\
\hline & & & & \\
Cytosine & 1.18 & 0.58 & 1.5 & 5.0 \\
Cytidine & 1.20 & 0.51 & 1.7 & 5.6 \\
CMIP & 0.64 & 0.31 & 1.7 & 5.6 \\
CpC & 1.69 & 0.53 & 2.3 & 7.6
\end{tabular}

a Taken with permission from reference [2]- 
In contrast to the behavior of the adenine sequence (Table $I$ ), $D$ data for cytosine and some of its derivatives (Table 2 ) indicate that the ribose group has little effect on diffusion while the phosphate group appreciably slows it down [2]. Thus, in the diffusing cytosine species, the pyrimidine ring plane may be perpendicular to the interface with the ribose group being behind the ring and adding little to the effective diffusional cross-section area ; the phosphate group, however, sticks out to one side of the molecule, increasing that area. $D$ for $C_{p} C$ indicates an effective area similar to that of cytosine or cytidine, suggesting a somewhat different orientation for $\mathrm{CpC}$ since its cross-sectional area in the stacked configuration has to be greater than that of CMP if the molecule diffuses with its rings perpendicular to the interface. The slightly greater temperature coefficient for $\mathrm{CpC}$ probably reflects the expected change in intramolecular association with temperature.

\section{Degree of association in solution}

The generally observed increasingly negative $U_{\mathfrak{I}}$ with increasing concentration of nucleic acid bases and their ribosophosphate derivatives $[\mathrm{r}-4]$ is in agreement with asscciation making reduction more difficult. Correspondingly, $I_{d}$ decreases with increasing concentration due to the decreased $D$ of the associated molecules.

For example, the predominant mode of association of purines, which usually associate to a greater extent than pyrimidines, is rertical stacking due to hydrophobic interaction of bases [5-7]. Since the standard free energy for such association is of the order of the thermal energy, the stacks break and reform rapidly with increased stability at lower temperature, $e_{-} g$, the relative decrease in $\boldsymbol{I}_{d}$ for an adenine nucleosidenucleotide sequence with increasing concentration was 2 to 3 times greater at $1.5^{\circ} \mathrm{C}$ than at $25^{\circ} \mathrm{C}[\mathrm{I}]$.

Unfortunately, adsorption at the interface on increasing concentration may also change $I_{d}$ and, more particularly, $U_{\%}$, making difficult interpretation of the polarographic data solely in terms of association in solution; however, reasonable assumptions permit comparisons to bc made, e.g., in resepct to the concomitant occurrence of adsorption and solution association in the cytosine series [3]. The increasingly negative $U_{\text {iz }}$ for $\mathrm{CpC}$ with increasing concentration (Fig. I) after reaching maximum coverage of the electrode with the adsorbed reduced species (ca. $0.3 \mathrm{~m} M)$, may be due to intermolecular interactions. Extrapolation of

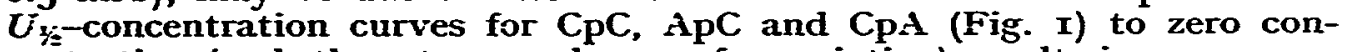
centration (and, thus, to zero degree of association) results in a common $U_{y=}$ at about $-\mathrm{r} .37 \mathrm{~V}$, compared to $U_{y / 2}$ of $-\mathrm{r} .3 \mathrm{~S} \mathrm{~V}$ for adenosine and cytidine at the pH involved. The increasing $U_{3:}$ differences between the three compounds with increasing concentration is likely due to increasing differences in the extent of association, with the latter being greatest for CpA, at least below $0.2 \mathrm{~m} M$.

$\mathrm{Di}-$ and oligonucleotides generally show strong intramolecular as well as intermolecular association, e.g., Refs. 8 -Io. The $U_{\text {绝 }} v s$. concen- 


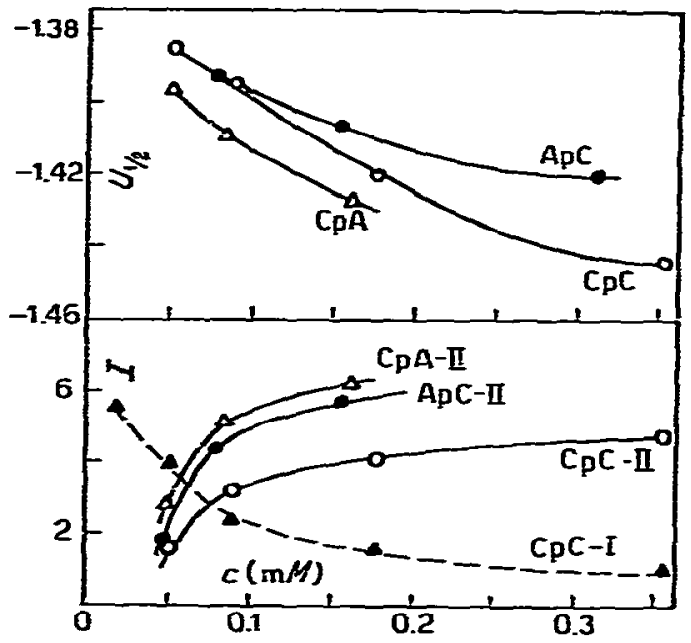

Fig- $x$.

Variation of haif-wave potential, $U_{Y,}$, and diffusion current constant, $I$, with concentration of dinucleoside monopiosphates in pH 5.0 MCInvare buffer (ionic strength $=0.13$. II) at $0.5{ }^{\circ} \mathrm{C}$. Roman numerals refer to the waves of each compound. (From Ref. 3 with permission;.

tration curves for the adenine oligomers, ApA to $(A p)_{5} A$, as well as for adenine itself, extrapolate to a more or less common $U_{y=}$ of $-I .23 \mathrm{~V}$ at zero concentration (and zero degree of association) [2]. The increasing differences in $U_{2}$ between adenine oligomers with increasing concentration can then be related to increasing differences in the degree of interaction, e.g., association and adsorption; the decreased $U_{z=}$ increment for each adenine moiety added to the chain indicates that these effects may level off at some higher chain length.

In terms of the farudaic current observed, a complication, which could be introduced by stacking of molecules, may be pertinent to interpretation of the current observed for large nucleic acid entities and other macromolecules. Diffusion of vertical stacks to the interface should be compatible with the model proposed for monomers [I], i.e., purine ring plane perpendicular to the electrode. Although arrangement of individual molecules in the stacks is often uncertain, in some models favored for purine nucleosides, pyrimidine ring faces pyrimidine ring with the ribose moieties being opposite to one another in the stack [II, I2]; however, the presence of protonated $N(x)$ tends to favor alternate stacking (pyrimidine facing imidazole) due to the reduced electrostatic repulsion. Alternate stacking better explains a relatively strong effect of even low concentrations on $D$; blockage of electrochemical redox sites could occur in stacked molecules that approach the interface with alternate pyrimidine rings oriented away from the surface. 
Di- and oligonucleotides, as noted, are expected to approach the interface with their base planes essentially perpendicular to the electrode. The right-hand screw conformation of dinucleotides [ro] allows the reduction sites in all adenine and/or cytosine moieties to approach the interface at the same time without substantial rotation or reorientation of bases; rotation may be, however, required in long-chain oligoor polynucleotides. Consequently, adenine di- and short oligonucleotides are generally more easily reducible than adenosine or AMP because of the extra energy needed for orientation of alternate stacks [ $\left.I, I_{3}\right]$ in the case of the latter two compounds, $i . e$. , extra energy would be needed to reduce those adenine moieties which approach the interface with their pyrimidine rings oriented away from the surface.

Although stacking cannot be at present evaluated quantitatively from polarographically measured diffusion coefficients, the relative variation of $D$ with concentration provides a possible means of identifying the presence of stacking at concentrations below $I \mathrm{~m} M[2,3]$.

It is apparent that quantitative - and even reliable qualitative interpretation of the polarographic data seen for DNA, RNA, and their large fragments in aqueous media will have to take into account the effects of association in solution upon the observed behavior. Application of some of the arguments just outlined are illustrated in an examination of some nucleosides $\left[\mathrm{I}_{4}\right]$.

\section{Medium effects}

The importance of the medium was recently stressed by PaLEcEK and KWEE [I5], who emphasized that the behavior seen for double stranded DNA at the mercury electrode, including the course of interfacial events, differs markedly for neutral and acidic aqueous media.

A marked difference in conformation of a molecule in different solvents could be detected from the variation in the $\eta D$ or $I_{M} \eta^{1 / 2}$ products, where $r_{i}$ is the solution viscosity. For example, $\boldsymbol{I}_{d}$ for methylnicotinamide in acetonitrile, $A N$, is about 2.4 times that in DMSO ; however, this only reflects the difference in $\eta_{i}$; the $\eta_{i} D$ products $\left(X 10^{5}\right)$ is 0.72 in $A N$ and 0.74 in DiISO (Table 3) [16]. Equal concordance in the $I_{d} \tau_{i}^{1 / 2}$ product is seenfor pyrimidine reduction in three solvents involving four different studies (Table 3 ) [ 17$]$.

$D$, calculated from $I_{d}$ for a nicotinamide (NAD $\div$-related) sequence of compounds in nonaqueous media, decreases with increasing molecule size except for $D N A D^{-}$whose $D$ is much smaller than expected on the basis of the STOzES-EINSTEIN model. Although this anomaly may be, $a$ priori, due to greater solvation and/or association, the latter is more likely since $D N A D+$ differs from the other $N A D$ species in having a hypoxanthine moiety in place of the adenine moiety ; the presence of a hydroxyl group on hypoxanthine may favor association.

In nonaqueous media, $[18]$. neutral purine, adenine and other 6substituted purines are reducible (initial $\mathbf{I} \mathrm{e}^{-}$process) at potentials which are unavailable in aqueous media due to prior reduction of hydrogen 
ion, water or background electrolyte cation. Possible implications of this in respect to nonreducibility of adenine and cytosine in double stranded polynucleotides have been considered [3, 4, I9] (cf. discussion of Model Formulation : Nucleic Acid Species).

Table 3. Effect of solvent on polarographic parameters a.

\begin{tabular}{|c|c|c|c|c|c|c|}
\hline \multirow{2}{*}{ Solvent $c$} & \multicolumn{3}{|c|}{ Pyrimidine } & \multicolumn{3}{|c|}{ I-Methylnicotinamide ${ }^{b}$} \\
\hline & $U_{y \leq}(V)$ & $I_{d}$ & $\eta^{2}=I_{d}$ & $U_{3 \leq}(\mathrm{V})$ & $I_{d}$ & $r_{i}=I_{d}$ \\
\hline $\begin{array}{l}\mathrm{CH}_{3} \mathrm{CN}_{\mathrm{N}} \\
(0.3+2)\end{array}$ & $-2-337$ & 3.39 & 1.98 & $-\mathbf{r . 0} \mathbf{f}$ & $3 \cdot 3$ & 1.93 \\
\hline$[36]$ & $-2-34^{\circ}$ & $3-5^{8}$ & 2.09 & & & \\
\hline $\begin{array}{l}\text { DMF } \\
(0.796) \\
{[27]}\end{array}$ & $-2 \cdot 3+4^{d}$ & 2.24 & 2.00 & & & \\
\hline $\begin{array}{l}\mathrm{H}_{2} \mathrm{O} \\
\left(0 . \mathrm{Sg}_{4}\right) \\
{[93]}\end{array}$ & $\begin{array}{l}-0.57^{6} \\
-0.105 \mathrm{pH}\end{array}$ & 2.12 & 2.00 & $-\mathbf{r . 0 3}$ & x.94 & $\mathbf{r} . \mathbf{S}_{\mathbf{3}}$ \\
\hline $\begin{array}{l}\text { DAISO } \\
(1.996) \\
{[+7]}\end{array}$ & & & & $-\mathbf{r . o I}$ & $1-4$ & I.98 \\
\hline
\end{tabular}

a Data taken from references 16,17 and 40.

- 1-methyl-3-carbamoylpyridinium ion. MICP+.

c Number in parentheses is the viscosity in centipoises: number in brackets is the dielectric constant.

d Potential vs. Ag| $\mathrm{AgCl}$ electrode in DMF ; other potentials are vs. SCE.

Conformation at the solutionjelectrode interface

In attempting to interpret phenomena at the solutionlelectrode interface involving electroactive molecules, consideration should be given to the most likely electron transmission path between electroactive site in the depolarizer and the electrode, as well as to possible alternative paths, e.g., one involving an adsorbed layer interposed between electrode and depolarizer in solution. The problem is obviously connected to con- 
formation of the depolarizer and its orientation in respect to the interface as a function of electrode potential. The probable orientation may be deduced from capacitance, faradaic and other measurements reflecting the composition and/or the structure of the electrical double layer, which may be pragmatically identified with the interfacial region or interphase. Such deductions usually involve prior determination of

(a) saturation coverage of the interface under various conditions, i.e., adsorbate concentration per effective unit electrode area, and

(b) probable effective areas of the adsorbate in its various forms (e.g., open or folded) and possible orientations (e.g., principal adsorbate plane parallel or perpendicular to the interface).

The orientation of individual and stacked (associated) models has been perceptively discussed by VETTERL, e.g., Fig. 2 [r4] depicting various situations for adsorption of a nucleoside. Similar attempts to depict graphically the accomodation and interaction with the interface of increasingly detailed formulations of increasingly large molecules cannot help but be informative and stimulating, $e_{-g} g$., the use of molecular models
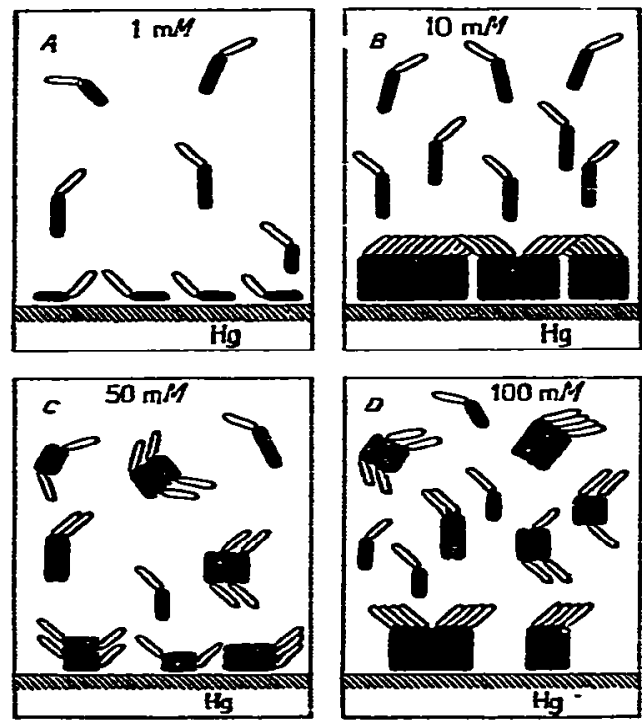

Fig. 2

Possible orientations of inosine molecules and/or stacks on the electrode surface at different bulk concentrations. Short black segments: base moiety (hypoxanthine). a view in the direction of the long axis ; long black segments: base moiety. a view in the direction of the short axis; empty segments : ribose moiety. $d: 1 \mathrm{~m} M$, planar adsorption $; B: 10 \mathrm{~m} . M$. adsorption and association of perpendicularly oriented molecules: $C=50 \mathrm{~m} M$, adsorption of stacks with no association at the electrode: $D=150 \mathrm{~m} . \boldsymbol{L}$, reorientation of stacks at the electrode and association of stacks. (From Ref. I+ with permission). 
of $\overline{5}^{\prime}$-AMP to illustrate its spacial arrangement when adsorbed at a mercury surface (Fig. $S$ of Ref. 20). The present authors have found spacefilling models of the CPK type [2I] to be useful in rationalizing orientation situations.

As VETTERL, et $a l$. [14] have recently summarized for the bases and VAlENTA, et al. [22-26] have shown for mono- and oligonucleotides of adenine and mononucleotides of cytosine, all investigated nucleic acid bases and nucleosides are adsorbed at a mercury electrode in the electrocapillary maximun vicinity; some are also adsorbed on the negatively charged electrode. At higher surface concentrations, most of the bases, nucleosides, nucleotides and oligonucleotides reorient from a planar to a perpendicular position and associate to form a surface film, which produces a pit on the capacitance curve, $e . g .$, the behavior of adenosine [27] and studies by Brabec, Christiax and Drymurst et al. (e.g., Refs. $2 \mathrm{~S}-30)$. The reorientation is caused by steric interactions, stacking forces and electrostatic interactions.

\section{Adsorption at the interface}

The complexity of adsorption on electrodes - actually at the solt tionfelectrode interface - is indicated by the controversial interpretations of the behavior of nucleic acid macromolecules to which reference has been made.

At sufficiently high solution concentration, all substances produce the measurable effects of adsorption at the interface, i.e., the displacement of solvent and for background species from the interface. Adsorption of a given compound at a specific interface is primarily a function of

(a) the chemical nature (including conformation) and concentration of the compound,

(b) the solution composition (including surface-activity of the components and ionic strength),

(c) the electrode composition (including its previous history if of a solid material), and

(d) temperature.

Any change affecting solubility of the compound will correspondingly affect its interfacial surface-activity, e.g., increasing its concentration. increasing the ionic strength or lowering the temperature will usually increase the extent of its adsorption. In the case of biopolymers, adsorption time is also an important parameter; for steady-state adsorption coverage, a bulk solution dependence exists only for mononucleotides and to a limited extent for oligonucleotides; adsorption for oligonucleotides in general and for polynucleotides is irreversible and steady-state adsorption is only attained at a unity degree of coverage (cf. Fefs. 24 and $3 r$, and subsequent discussion of $\mathbf{N A D} \div$ adsorption).

An important aspect of adsorption studies, as noted, is often that of determining the electrode area effective or available for adsorption 
when electrochemical approaches involving various time scales and assumptions are used to evaluate adsorption, e.g., studies on the effective area at mercury electrodes [32-34] and at solid electrodes (carbon ; platinum ; gold) $[35-37]$.

Comparative studies of 6 -substituted purines $[3 S]$, and adenine and cytosine nucleoside-nucleotide sequences and di- and oligonucleotides $[\mathrm{r}-3]$ show the complicated adsorption patterns of these compounds as well as the influence of adsorption on their observed behavior. Studies of the nicotinamides [39-4I] show similar complications due to adsorption. One important factor is the association in the adsorbed state, which has been extensively investigated for the bases by VETrERL, et al. [I4, $42,43]$ and for mono- and oligonucleotides by VALENTA, et al. [23-25].

A recent examination [44] of adsorption of adenine at the aqueous solution/mercury interface, in which surface charge, surface tension and adsorption isotherms were derived from a.c. polarographic capacitance curves, indicated that adenine molecules are adsorbed at all $\mathbf{p H}$ in a flat orientation due to specific $\pi$-orbital interaction, which, in acidic media, predominates over electrostatic repulsion between protonated adenine and positively charged electrode. The extent of adsorption increases with $\mathrm{pH}$ in McILvirie buffer ( $\mathrm{pH} 2.6$ to 7.2 ) but is less in pH 9.0 carbonate buffer than in pH 7.2 IICILvarie buffer. IVith increasingly negative electrode potential or charge, the surface excess of adenine steadily decreases; adenine is not adsorbed negative of -r.6 $\mathrm{V}$. There is neither potential-ror surface-charge-dependent reorientation at potentials more negative than $c a$. - I.I $V$; a concentration-dependent reorientation occurs before monolayer coverage is complete. Adsorption can be described by a Fruakr isotherm with an interaction factor corresponding to attraction between adsorbed molecules for potentials positive of $-0.7 \mathrm{~V}$ at $\mathrm{pH} 7.2$ and $-0.5 \mathrm{~V}$ at $\mathrm{pH}$ 9-0. Fespulsion between adsorbed molecules at $\mathrm{pH} 3 . \mathrm{S}$ implies the presence of protonated adenine on the surface. The standard free energy of adsorption varies from -7 to $-9 \mathrm{kcal} / \mathrm{mol}(-29$ to $-3 S \mathrm{~kJ} / \mathrm{mol})$. The data are in quantitative agreement with those for the adenine nucleotides [23].

\section{Adsorption sites}

In specifying adsorption sites of a molecule, one must cope with the fact that adsorption at mi rcury and other electrodes can be due to a variety of causes and of paible adsorption configurations in compounds, $e_{-g}, \pi$-bonding involving aromatic rings, specific bonding involving particular nitrogen atoms, $\mathrm{C}=\mathbf{N}$ double bonds and oxygenated sites, and chemical binding involving negatively charged phosphate groups and metal complex formation. Thus, in adenine, $N(7)$ and the extracyclic nitrogen at $\mathrm{C}(6)$ provide the steric configuration necessary for metal chelation via five-membered ring formation.

Di- and oligonucleotides, which are susceptible to vertical overlapping or stacking of their bases, are very strongly adsorbed, indicative of an increase in adsorption sites and ring interactions in the stacked 
conformation, e.g., Refs. 3 and 24. They are adsorbed with rings planar to the electrode surface with a maximum of four rings being thus oriented in the case of adenine oligomers. Most exhibit $\mathrm{pH}-$ and concentrationdependent self-association in the adsorbed state, even from very dilute solution.

Increasing complexity of structure in large molecules may favor adsorption due to the presence of an increased concentration of adsorption sites in the molecule as well as increased association in the stacked configuration due to ring interactions. On the other hand, a more or less rigid structure may lower the effective concentration of adsorption sites due to some of them not being favorably located for interaction with the electrode surface (cf. previous discussion of alternate stacking).

\section{Model formulation : Nucleic acid species}

Models, which may be formulated to rationalize the electrochemical observations made on nucleic acids and their massive fragments, in addition to specifying, inter alia, $\mathbf{p H}$, electrode potential range, and electrochemical technique (e.g., small or large voltage changes during DME drop-life), have ultimately to deal with such difficult problems as the following:

I. There is a real need for increasing the bridging and correlation of the observatiors made on large entities with those made on very much smaller presumed model species, e.g., di- and oligonucleotides based on adenine and cytosine.

2. The conformation and adsorption sites of adsorbates at solution| electrode interfaces need to be better established ; this may involve comparison of the experimentally determined effective interfacial area occupied by an adsorbate molecule with the areas calculated for different adsorbate conformations and orientations.

3- The adsorption site problem needs to be related to that of the approach to the electrode of electroactive sites in soluble and adsorbate molecules; this may involve formulation of the likely electron transfer path in faradaic processes, e.g., on reduction of NAD $\div$, how does the electron reach the pyridine ring when $\mathrm{NAD}^{+}$is adsorbed in the folded configuration with the adenine ring interposed between electrode and pyridine ring, and how is the path altered when adsorption of $N A D \div$ and its reduction products is prevented by the presence of a tetraalkylammonium ion which is preferentially adsorbed at the potential of $N A D^{-}$reduction. This is connected to the general question of mediator action as is readily apparent in chemically modified electrodes including electrode surfaces altered by oxidation or chemisorption of solution species.

Based on their behavior in aprotic media, the non-reducibility of the bases in double stranded polynucleotides can be ascribed to the lack of available potential range in aqueous media [4] ; interstrand hydrogenbonding in the double stranded configuration sufficiently stabilizes the 
bases to prevent their protonation as is necessary for their reduction in aqueous media. The latter statement is regarded by some as having been established. [19, 22, 3r, 45-55] From such a viewpoint, it follows that, as long as the WATSON-CRICK interstrand hydrogen bonds are intact, proton and electron transfer to the most readily reducible sites in adenine and cytosine ( 1,6 and $3,4 N=C$ double bond, respectively) cannot occur. Only in those sections, for example, of the native DNA polynucleotide where the helix has been opened and where WATSON-CRICK bonding is no longer operative, is reduction of the adenine and cytosine moieties possible. Helix opening can be caused by adsorption forces and the interfacial electric field, $e$.g., Refs. $3 I$ and 45 by the Jülich group and 56 and 57 by the Brno group and subsequent discussion.

On the other hand, others have indicated that they have no experimental evidence (a) that electron uptake demands an unwinding of the helix and (b) that cannot be explained by a mechanism whose controlling factor in respect to the possibility of reduction is the adsorbability limit at negative potential.

It would seem to be significant that, even at less than $I \%$ statistical fluctuation (breathing), the double helix can take up large heavy metal ions to form inner complexes without losing its stability, e.g., formation of cross-links with $\mathrm{Hg}(\mathrm{II})$ [5S-6r] and $\mathrm{Ag}(\mathrm{I})$ [62].

The model proposed for electrochemical reduction of DNA and other massive nucleic acid species by the Jena group is typified by Fig. 3 , in which five surface effects are involved $\left[6_{3}-6_{5}\right]$. The possibility of en-

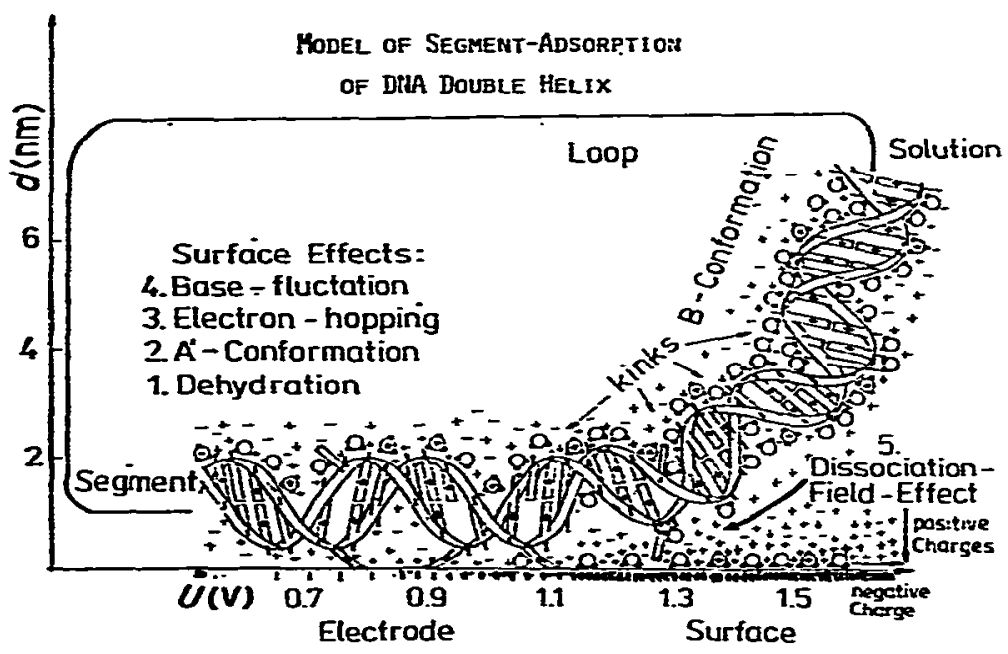

Fig. 3.

Model for adsorption by segments of the DNA double helix. Circles with two dots near them represent $\mathrm{H}_{2} \mathrm{O}$ : circles with three dots and a plus sign, $\mathrm{H}_{3} \mathrm{O}^{+}$; rectangles. bases : rectangles with plus signs, protonated bases; short vertical lines, electrons ; short horizontal lines, anions: plusses, cations. (From Ref. 6.4 with permission). 
hanced fluctuation of the bases is necessarily coupled with an effective opening of the biopolymer structure. In the diagramatic expression of Fig. 3, with increasing negative charge on the electrode, the ratio of cations to arions in the double layer changes, as does consequently the counter-ion condensation or dissociation on the contact side of the segments. The surface effects indicated may occur, leading to reduction without strand separation. A helix unwinding or even a strand separation preliminary to electrochemical reduction is considered as not yet proven; this would seem to be the crucial difference from the conceptions of the Brno and Jülich groups, e.g., Fefs. 15,50 and 66 , in which the differences between unwinding, denaturation and base fuctuation at the electrode surface are considered to be semantic; if opening, $i_{.} e_{.}$, fluctuation, of bases of the double helix is accepted as the necessary condition for reduction, there would seem to be no important discrepancy between the views. The matters in dispute also involve such related questions as to whether double helical DNA is denatured before electron up-take through partial unwinding (Brno) or even through single strand separation (deconformation) (Jülich).

There may be some agreement between the Brno and Jena groups (1977 Weimar Symposium: Fefs. 63 and 67) that, when a kink in the DNA adheres to the electrode surface (Fig. 3 and 4 ), unwinding may not be necessary for enhanced base fluctuation to result in electron up-take. REYxaUd [6S], in connection with a proposed scheme for the electrochemical behavior of native DNA at the mercury electrode, compared his model for adsorption of native DNA with those proposed by the Brno, Jena and Jülich groups. Subsequently, he [69] proposed a general pattern for the behavior of native DNA and its polynucleotide derivatives at an interface with the following essential features:

(a) adsorption at and near the electrocapillary maximum (weak field) is principally due to the sugar-phosphate groups;

(b) peak I at ca. -I.I $V$ is capacitive and due to base reorientation at the interface ;

(c) peak 2 at ca. $-\mathrm{I}$-35 $\mathrm{V}$ is due to irrerversible reduction of adsorbed bases to adsorbed products below pH 6 and to desorption of the macromolecules above pH 6 ;

(d) peak 3 et ca. $-\mathbf{I}-5 V$ is the true reduction peak of the adsorbed bases, with which a catalytic effect is associated :

(e) peak 4, seen at ca. $-\mathbf{r} .5 \mathrm{~V}$ for methylated DNA, is ascribed to reduction of cytosine and 7-methylguanine moieties.

Basic information and assignments for REYxaud's model are contained in Refs. $45,4 S$ and 70 ; peak 2 is assigned to non-faradaic reorientation of the bases with catalytic hydrogen evolution following base reduction peak 3 at slightly more negative potential $[45,4 \$]$.

In developing a more graphic model of the adsorption (Fig. 4), ReYNaUd [69] uses the breathing of DNA (the fact mentioned that ca. $I \%$ of the bases are at any point in time opened, i.e., in contact with the 
solvent). In the electrocapillary maximum region, adsorption initially involves only sugar-phosphates (areas $A$ and $B$ ) ; then, due to breathing, bases at $A$ and $B$ can compete with the sugar-phosphates for adsorption on the electrode. At increasingly negative potential, the number of sugarphosphates available for adsorption decreases and, due to the breathing, bases become increasingly the adsorption links; beyond - r.o V, anchorage is due only to bases and DNA is probably denatured at areas in contact with the electrode.

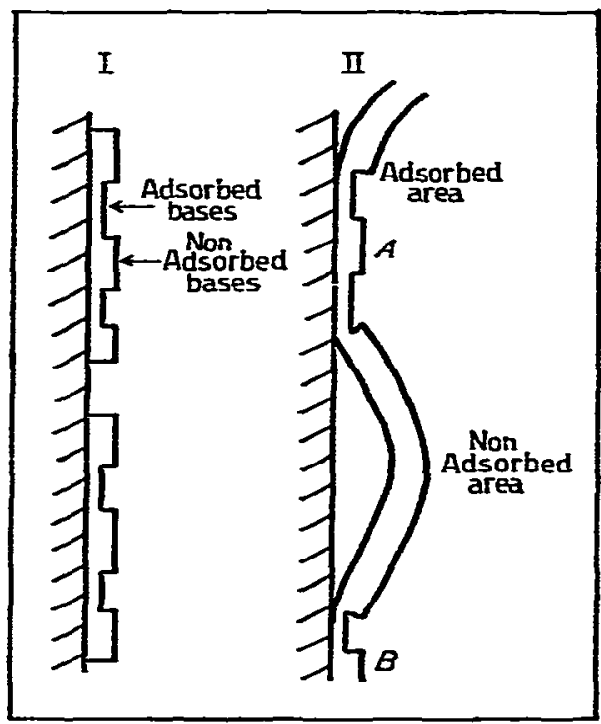

Fig. \&.

Pattern for DNA adsorption. I : Low molecular weight ; II : High molecular weight. (From Ref. 69 with permission).

FEYNAUD's model is interesting since it seems to embody many features of the views of the Brno, Jena and Jülich groups (cf. pages 3793So of Ref. 6S). The present authors consider the model to be useful, as REYNAUD indicates, as a basis for further investigation, e.g., interpretation of the constancy with $\mathrm{pH}$ of the differential capacitance ratio (as a function of potential) as adsorption being principally due to the sugarphosphates and not to the bases.

It is instructive to compare the sequences of events on adsorption, as proposed by the Jena group and by REYsiun, with that proposed by the Jülich group (Fig. 5) $[22,46]$ and with the conformational changes in DNA considered by the Brno group, e.g., F ef. 67. The latter group [ $\mathbf{r}_{5}$ ] has indicated that the scheme of Fig. 5 is not valid at neutral pH for the eiectrode charged to potentials of DNA reduction. 


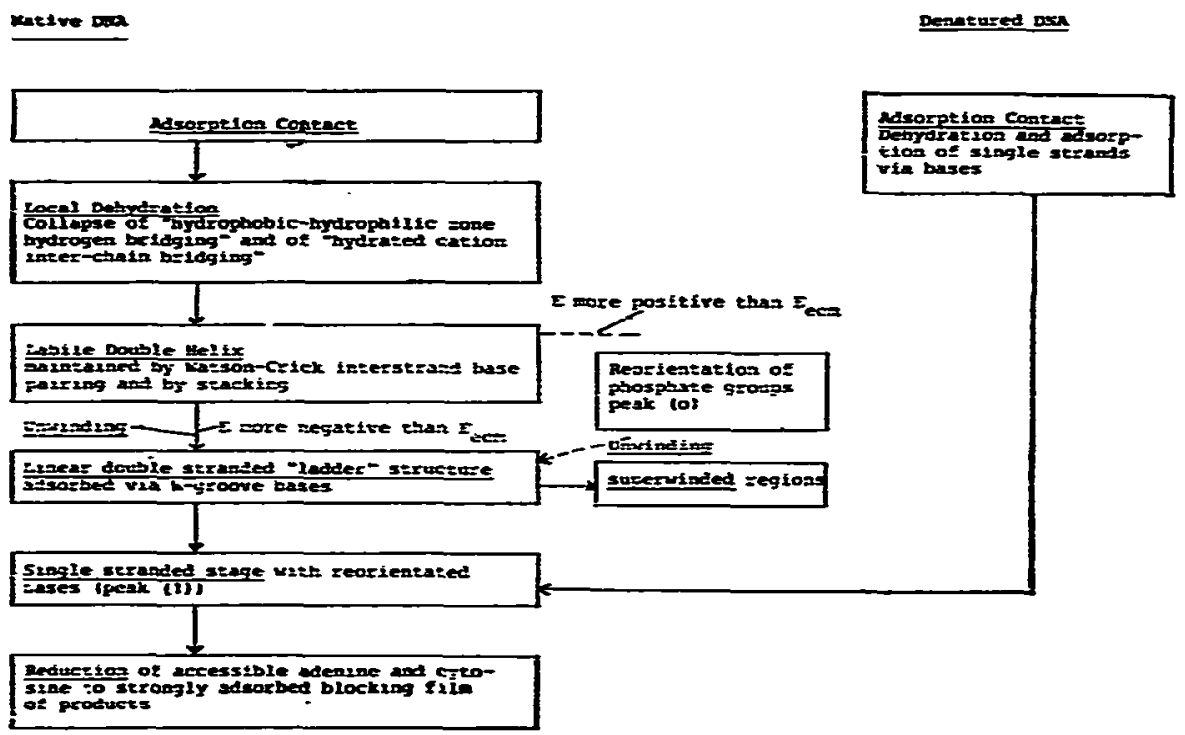

Fig. 5 .

Fow chart for the sequence of interfacial events involving native and denaturcd $D N A$ adsorbed at the mercury electrode. (From Ref. 46 with permission).

\section{KAD:- NADE Redox Couple}

The subsequent discussion is focused on the biologically important NAD $\div$-NADH coenzyme redox couple (Fig. 6), whose grossly reversible behavior under physiological conditions is indicated as

$$
\mathrm{NAD}^{+}+\mathrm{H}^{+}+2 \mathrm{e}^{-} \rightleftharpoons \mathbf{N A D H}
$$

with an apparent formal potential, $U_{c}^{\circ}$, at $\mathrm{pH} 7$ and $25^{\circ} \mathrm{C}$ of $-0.5^{6} \mathrm{~V}$ vs. S.C.E. Enzymatic reduction of $\mathrm{NAD}^{-}$results in addition of $H$ at $C(4)$ and loss of the quaternary character and positive charge at $N(I)$. Some of the features observed in electrochemical investigation of this couple and relevant related and model compounds in aqueous and nonaqueous media at mercury, platinum, gold, pyrolytic graphite and glassy (vitreous) carbon electrodes, are of general interest in respect to the behavior of nucleotides at interfaces.

Electrochemically, NAD ${ }^{*}$ (as well as other I-substituted nicotinamides) is reduced in aqueous medium at a D.M.E. in a reversible $I \mathrm{e}^{-}$ process at ca. -0.9 to $-x .0 \mathrm{~V}$ to a neutral free radical, which rapidly dimerizes (Fig. 7) ; at more negative potential, ca. $-\mathrm{r} .6 \mathrm{~V}$, the free radical is reduced in a $\mathrm{I} \mathrm{e}^{-}$reaction to the dihydropyridine; the latter is oxidized 


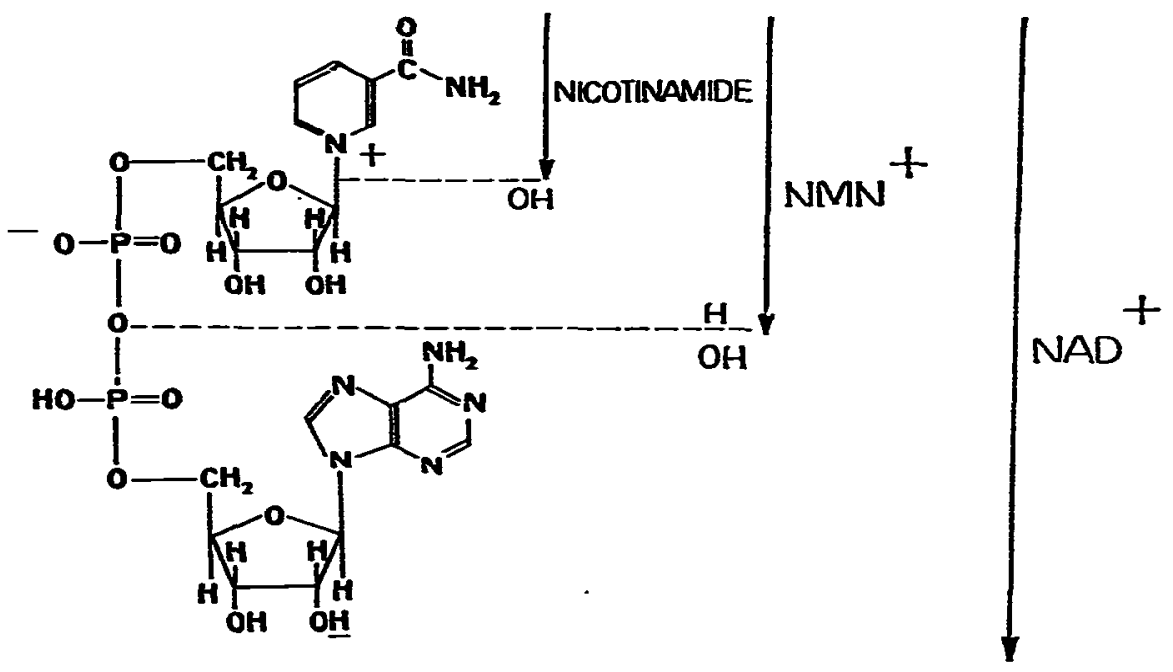

Fig. 6.

Formula of enzymatically active $\beta$-nicotinamide adenine dinucleotide (NAD+). Other names for this compound include diphosphopyridine nucleotide (DPN+), coenzyme $I$, codehydrogenase and cozymase. Nicotinamide mononucleotide is designated by NMN+.

at ca. $+0.6 \mathrm{~V}$; the dimer is oxidized at ca. $-0.2 \mathrm{~V} .[4 \mathrm{I}, 7 \mathrm{I}, 72] U_{3}$ for reduction wave $I$ is nearly independent of the medium (aqueous or nonaqueous; $\mathrm{pH}$; ionic strength), indicating the absence of significant ionpairing of the cationic molecule; however, $U_{1 \leq}$ is affected by adsorption of $\mathrm{NAD} \div$ and its reduction products (cf. next section).

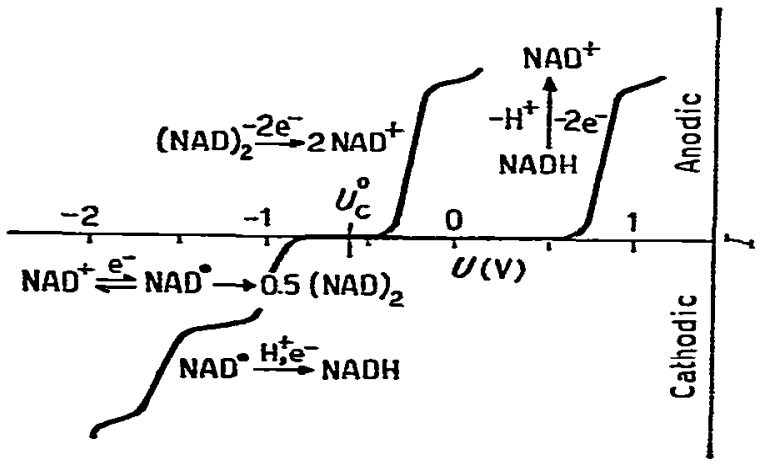

Fig. 7-

Composite representation of the voltammetric waves for the $N A D \div-N A D H$ system in relation to the calculated formal potential, $U_{c}{ }^{\circ}$ of $-0.557 \mathrm{~V}$ for the half-reaction, $N A D *+$ $+3 e^{-}+\mathrm{H}^{*} \rightleftharpoons \mathrm{NADH}$, at $\mathrm{pH} 7$ and $25^{\circ} \mathrm{C}$. Potentials are $v s$. S.C.E. (From Ref. 72 uith permission). 
Nuclear magnetic resonance, spectrophotometry and fluorescence show considerable interaction in solution between the nicotinamide and adenine moieties of $\mathrm{NAD}^{+}$with a large fraction of the dinucleotide being in a folded conformation [73-75]. It is obviously important as to whether the reducible species at the interface is folded or unfolded, especially if adenine is the adsorption site in the molecule (cf. subsequent discussion). There is the related question as to whether adenine could participate in the $N A D \div$ reduction with electrons received by it from the electrode being transferred to the nicotinamide. There is some question as to whether the adenine moiety of $\mathrm{NAD}$ - can be reduced electrochemically under the experimental conditions involved, e.g., at $\mathrm{pH} 7$ to ro [76]; it has been postulated in pulse radiolysis studies of $\mathrm{NAD}+[77]$ that, when an electron reacts with the adenine, it is rapidly transferred to the nicotinamide. In any event, orientation of $\mathrm{NAD}^{+}$at the interface is important in a number of respects. In adenine-cytosine dinucleotides, both bases can be electrochemically reduced in their normal overlapping $\mathbf{p H}$ ranges of electroactivity, i.e., $\mathrm{pH} 2$ to $5[3]$.

\section{$N A D^{+}$adsorption pattern}

The marked effect of adsorption on the NAD * polarographic pattern is evident (Fig. 8) on replacing $K \div$ by $E t_{4} N+$, which, at the concentrations involved, is more strongly adsorbed than $\mathbf{N A D}^{+}$or its reduction products. [4I]

In $\mathrm{KCl} /$ carbonate buffer, the capacitive current is depressed due first to $\mathrm{NAD}^{-}$adsorption and then to dimer adsorption up to a potential intermediate between waves $I$ and II (ca. $-\mathrm{I}_{-3} \mathrm{~V}$ ) where the dimer is desorbed; as the potential becomes mcre negative, $\mathrm{K} \div$ displaces the dimer probably because of increasing coulombic attraction of $K \div$ to the electrode and/or increasing repulsion of the negatively charged dimer phosphate groups from the electrode. During desorption, alteration of the mercury surface tension promotes solution stirring, thereby enhancing the wave I limiting current; the capaciave wave thus behaves similarly to maxima of the second kind.

In $\mathrm{Et}_{\mathrm{a}} \mathrm{NCl} / \mathrm{carbonate}$ buffer, the capacitive current, after a capacitive wave at $-0.6 \mathrm{~V}$, is essentially identical to that for background electrolyte alone. Before the capacitive step, $\mathbf{N A D} \div$ is adsorbed; after it, Et $\mathbf{N}_{4}$ is preferentially adsorbed.

Comparison of the behavior of $\mathrm{NAD}^{-}$and $\mathrm{NMN}-$ indicates the major role of adenine in the adsorption process. NMN $\div$, which represents the nicotinamide nucleotide portion of $\mathrm{NAD}^{-}$(Fig. 6), and its reduction products are negligibly adsorbed. NAD * behaves similarly to other adenine nucleosides and nucleotides [I] in being strongly adsorbed in the potential region prior to and in the vicinity of the electrocapillary maximum, and in producing desorption peaks at more negative potential. Similarly, the adenine or purine-related moiety of NADP ${ }^{*}, D N A D *$, DNADP ${ }^{\ddagger}$, and $\alpha-N^{-} D^{*}$ causes adsorption behavior characteristic for each compound [4I] ; on $\mathrm{Et}_{\mathbf{4}} \mathrm{NCl}$ addition, adsorption is minimized beyond 
the electrocapillary maximum due to preferential adsorption of $E t_{\mathbf{t}} \mathbf{N}$ : and the polarographic patterns are then very similar to that of NMN:Ar often complicating fact of life is a catalytic hydrogen evolution associated with even weak and low surface coverage due to adsorption of the reduction products of the pyridine-related compounds and a socalled surface catalytic wave [40].

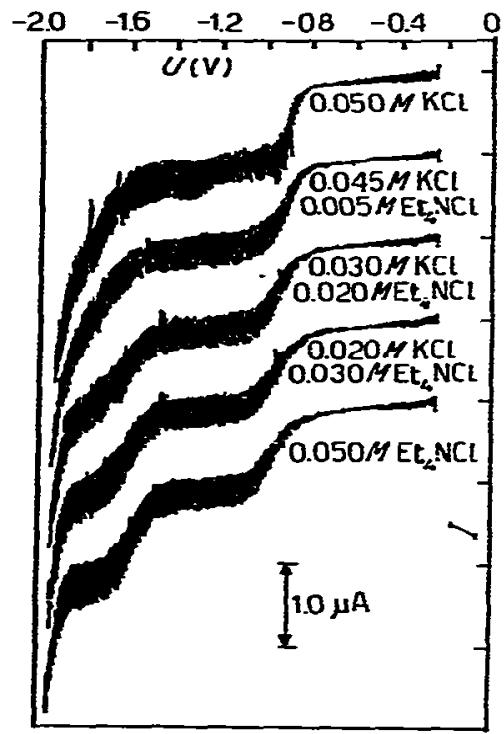

Fig- S.

Variation in the d.c. polarographic behavior of $\mathrm{NAD}+(0.3 \approx \mathrm{m} . \mathrm{N})$ with increasing $\mathrm{Et}_{4} \mathrm{NCl}$ concentration at constant o.ro $M$ ionic strength $\left(0.0_{5}\right.$ iI carbonate buffer plus $\mathrm{Et}_{4} \mathrm{XCl}$ and $\mathrm{KCl}$ as shown: final pH 9-9). (From Ref. fI with permission).

\section{NiDH adsorption pattern}

The voltammetric patterns seen on oxidation of $\mathrm{NADH}$ at a variety of solid electrodes in aqueous and non-aqueous media $\left[35^{-}-37,71,78,79\right]$ are determined, inter alia, by the following :

(a) concentrations of NADH and its oxidation products;

(b) the electrode material, configuration used, and treatment and conditioning ;

(c) medium composition (solvent; background electrolyte components, especially in respect to their surface-activity; proton activity; ionic strength); and

(d) nature and operational characteristics of the technique used, including potential scan range, polarization or scan rate $(\mathrm{d} U / \mathrm{d} t)$, timing sequence for perturbation methods, and, in general, the temporal pattern for the overall experiment. 
On pulse polarography in aqueous medium at rotated pyrolytic graphite (PGE) and glassy carbon (GCE) electrodes, a single maximumshaped wave is seen below ca. O.I $\mathrm{mM}$ NADH (Fig. 9: curve $B$ ). The maximum shape is progressively attenuated with increasing NADH concentration; no maximum is detectable at o.I5 mM NADH. At higher concentration, a second wave appears (curve $A$ ); then, for a given time interval between successive pulses, the sum of the two wave heights is proportional to the bulk NADH concentration.

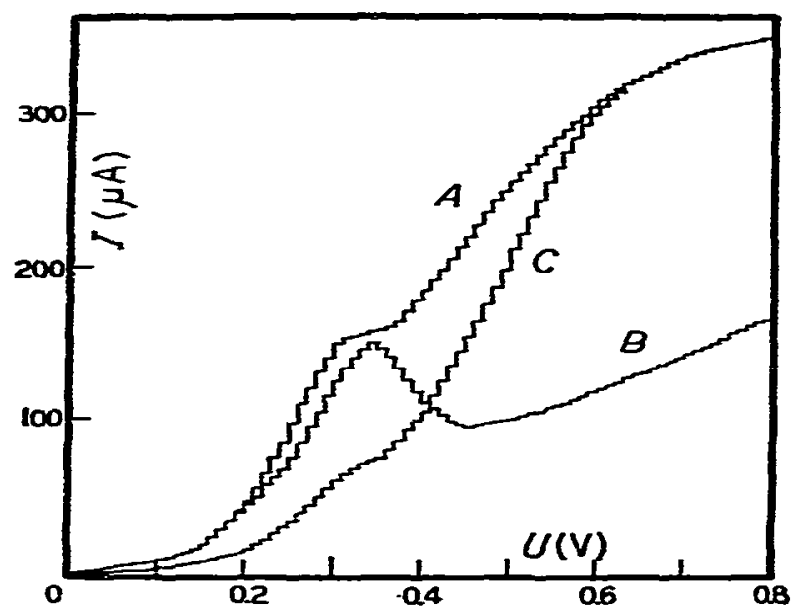

Fig. 9 .

Dependence of the normal pulse polarogram at a rotated pyrolytic graphite electrode $\left(f=10\right.$ r-p.s.) on $\mathrm{NADH}$ concentration in $0.18 \mathrm{M} \mathrm{Na} \mathrm{SO}_{\mathrm{t}}$ and $0.05 \mathrm{M}$ PH 7.0 phosphate buffer at $25^{\circ} \mathrm{C}$. Scan rate $=2 \mathrm{mV} / \mathrm{s}$. Pulse characteristics : time interval between succossive pulses $=5 s$ : sample duration time at the end of each pulse $=5$ ms. NADH concentration. mII : $-1.0 .7 \mathrm{~S} ; B, 0.10 ; C .0 .7 \mathrm{~s}$ with $0.64 \mathrm{~m} M \mathrm{NAD}+$ added. (From Ref. 35 with permission).

Pulse polarography and single sweep voltammetry clearly support the presence during NADH oxidation at carbon electrodes of a preprocess as expected for strong adsorption of the product of an electrochemical process, e.g., peak I height on voltammetric sweep at a stationary electrode increases linearly with scan rate, $v$, while peak II height increases as $v^{1 / 2}$ (Fig- Io). The prewave is due to the reaction,

$$
\mathrm{I,4}-\mathrm{NADH} \rightarrow \mathrm{NAD} \div \mathrm{ads}+\mathrm{H}^{\div}+2 \mathrm{e}^{-}
$$

The pyridine ring produced in reaction 6 would be expected to play an important role in the adsorption of $\mathrm{NAD}^{+}, e . g$, in binding between the aromatic pyridine and adenine rings and the partial aromatic carbon electrode surface. 


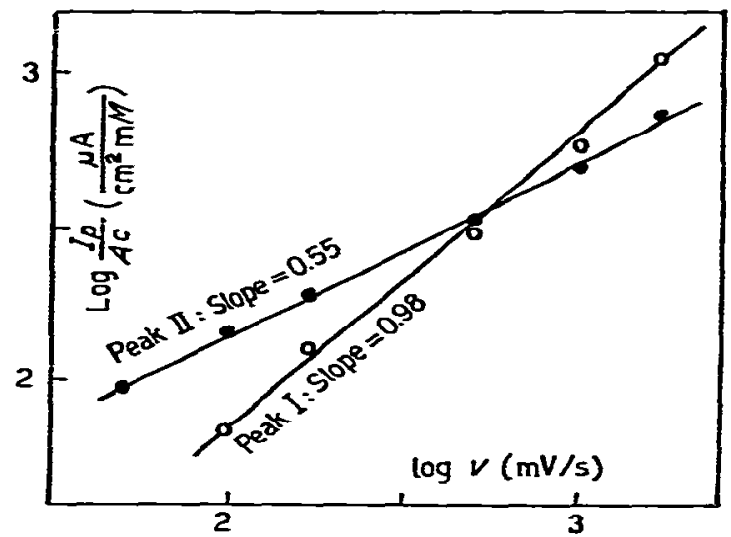

Fig. 1o.

Effect of scan rate, $v$, on the peak height at a stationary glassy carbon electrode for $r$.o6

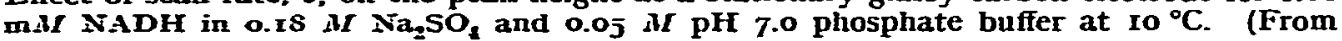
Ref. 35 with permission).

NADH itself may be weakly adsorbed at carbon electrodes but clear evidence is not available, e.g., the capacitive current is too large at high $v$ for reliable measurement and it is not possible to see if both peaks increase linearly with $v$ as should occur when the reactant is adsorbed and $v$ is large.

First covering the carbon electrode surface with a layer of strongly adsorbed electrochemically generated $\mathrm{NAD} \div$ eliminates the overlapping wave problem by suppressing the prewave $[78]$; such a covered electrode can be repeatedly used for NADH measurement without further pretreatment. The voltammetric pattern is so reproducible in spite of the poor shape of the observed curve (Fig. II), that analytically satisfactory results can be obtained at the millimolar NADH level by simply subtracting from the test solution current, measured at a potential on the rotating disk electrode (RDE) limiting current plateau, the background solution current at the same potential; a comparably simple procedure can be used at the micromolar level.

\section{Conformation of NAD species adsorbed on carbon electrodes}

The following hypotheses, subsequently developed in detail, have been proposed as providing the most economical explanation of the observed behavior (occurrence of a fast process ; occurrence of a slow process producing strongly adsorbed $\mathrm{NAD}^{+}$; area occupied by one molecule of strongly adsorbed NAD*; difference between adsorption behavior of ADPR and NAD*) [35-37]. 


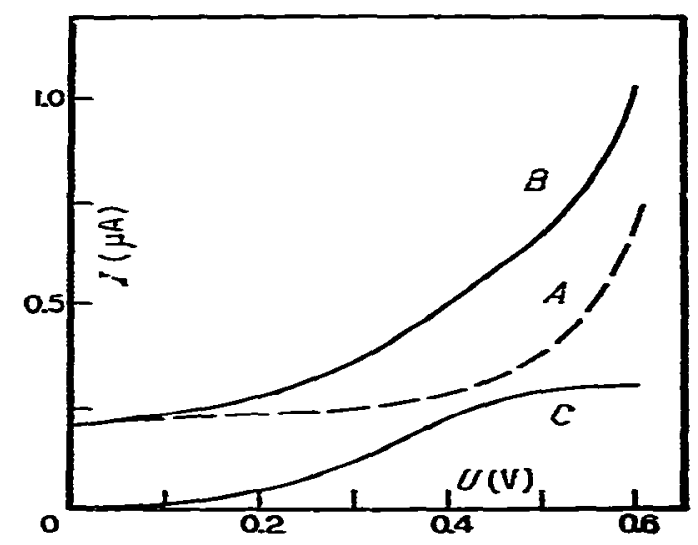

Fig. II.

Voltammetric curves at $v=2 \mathrm{mV}^{-1}$ at a rotating glassy carbon electrode (ro r.p.s.). covered with adsorbed $\mathrm{NAD}+$ for $\mathrm{N} \mathrm{ADH}$ in $0.5 \mathrm{M} \mathrm{KCl}$ and $0.05 \mathrm{II}$ Tris buffer (pH 7 -I.). $A$ background : $B:+.9 \mu, M Y \perp D H ; C$ : curve $B$ corrected for background current. (From Ref. $7^{S}$ with permission).

At carbon electrodes, $\mathrm{NAD} \div$ produced on anodic oxidation of $\mathrm{NADH}$ is first rapidly adsorbed in a planar configuration relative to the electrode surface (Fig. 12). The adsorbed molecules then relatively slowly reorient to a state perpendicular to the electrode, which is more tightly bound to the surface than the planar oriented adsorbate. One-electron reduction of $\mathrm{NAD}$ - produces the dimer, which, at a clean GCE surface, involves both diffusion- and adsorption-controlled processes; the latter is due to formation of adsorbed dimer, which is more strongly adsorbed than NAD - The dimer is oxidized at the GCE only if it is adsorbed. There is no evidence to support adsorption of NADH to any appreciable extent on the carbon surfaces examined under the conditions used.

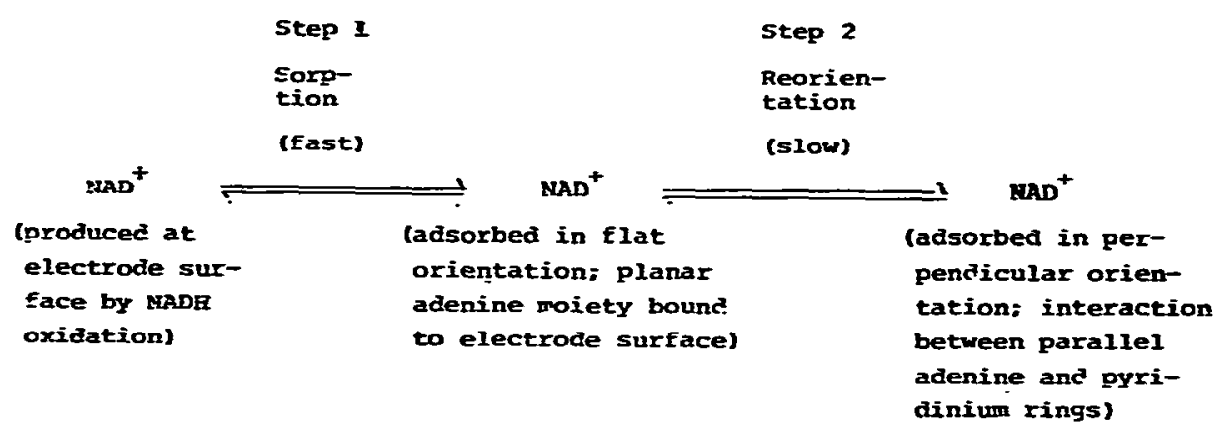

Fig. 12.

Adsorption sequence for $\mathbf{N A D}^{+}$produced by electrochemical oxidation at carbon electrodes. 
The assumption of two kinds of NAD - adsorption layers, as structurally defined, is justified but not conclusively established by the electrochemical data; however, it is in harmony with other explanations of the variation in behavior of adsorbed species $[14,42,43,75,80,81]$

I. Areas of NAD adsorbates. - The pertinent molecular areas involved in $\mathrm{NAD}+$ adsorption are as follows.

The adenine moiety, which is assumed to be the adsorption site for NAD; at mercury electrodes, $\left[76, S_{2}\right]$ may also be a site at the GCE. Planar adenine, based on its crystal structure, has in area of $42 A^{2}\left[S_{3}\right]$; considering its unsymmetrical shape and the resultant difficulty in packing on a surface, the area actually occupied was estimated to be 50 to $60 \AA^{2}$ and was found to be $55 \pm 4 \AA^{2}$ (capacitance curves at a mercury electrode) [So]. Since the same result was found with deoxyadenosine, the deoxyribose group was assumed to be tilted away from the surface. However, these areas do not apply to a flat orientation of the adenine portion of $\mathrm{NAD} \div$; if the $\mathrm{NAD}+$ conformation is that of a folded molecule with parallel adenine and pyridinium rings [73-75], the corresponding minimum projected area is at least $125 \AA^{2}$; the minimum projected area with the adenine and pyridinium ring planes perpendicular to the electrode surface is about $S_{5} \AA^{2}$.

2. Rapid adsorption : planar conformation. - Initially, a rather fast adsorption-desorption process occurs, probably involving planar adsorption of NAD+ which is bound to the electrode surface through the adenine moiety (Fig- $1_{3}$ ). This adsorption would account for the adsorption-controlled process observed on NALH oxidation. [35] As this process is rapid, equilibrium prevails between the activities of bulk solution and adsorbed $\mathrm{NAD}^{+}, e . g$, a $2 \mathrm{mM} \mathrm{NAD}^{\circ}$ concentration is sufficient to cause the adsorption-controlled process to disappear due to saturation coverage of the electrode surface (Fig. 9: curve $C$ ). Thus, the voltammetric adsorption-controlled process (prewave) may be hindered by prior coverage of the electrode surface with adsorbed $\mathbf{N A D}$ : as the result either of an electrolysis or of a relatively high $\mathrm{NAD}^{-}$solution concentration.

3. Slow reorientation: perpendicular conformation. - In a second step, a reorientation may slowly occur, leading to association of perpendicularly oriented adsorbed $\mathbf{N A D}^{-}$molecules (Fig. 13), for which there are two possible orientations; phosphate groups close to the electrode surface or the opposite. The negatively charged phosphate groups may be attracted by the positively charged electrode; on the other hand, the ribosophosphate groups are hydrophilic while the adenine and pyridine rings tend to be hydrophobic and to have an aromatic character favoring binding to the carbon ring structure of the electrode. In any event, an electrode so covered provides optimum reproducibility of voltammetric curves $[35,78]$.

In the perpendicular orientation, association can occur between the parallel adenine and pyridinium rings of stacked adsorbed NAD+ molecules as assumed in similar purine-pyrimidine cases. $[42,43, \mathrm{Sr}]$ 
Actually, such adenine-pyridinium interaction seems necessary in order to produce coverage of the electrode involving perpendicularly oriented adsorbed molecules [36].

Coulometric reduction of an electrode surface with effectively saturation coverage of adsorbed NAD* corresponded to $90 \pm$ Io $\AA^{2}$ per adsorbed NAD' molecule for monolayer coverage, which is in excellent agreement with that calculated for perpendicular orientation.

Slow desorption of the adsorbed NAD+ from a covered electrode also occurs. However, the dependence of desorption rate upon the electrode potential has not yet been systematically examined.

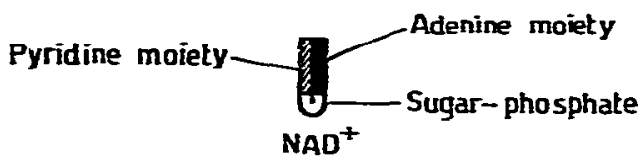

$\boldsymbol{A}$

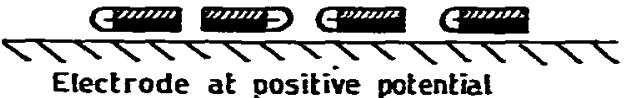

Electrode at positive potential

$\boldsymbol{B}$

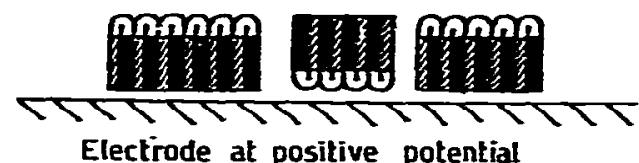

Fig. 13.

Schematic representations of possible orientations of $N A D=$ at an aqueous solutionjcarbon electrode interface. $A$ : planar adsorption. $B$ : adsorption and association of perpendicularly oriented molecules. (Firom Ref. 36 with permission)-

\section{Conclusions}

There is a continuing need to explicate the variation as well as the continuity in behavior seen between electrochemical investigations of pyrimidines, purines, and their simpler nucleosides and nucleotides, and similar investigations of polynucleotides and large nucleic acid fragments extending up to DNA and RNA species themselves. It is a tribute to both the daring and the scientific acumen of groups such as those at Brnc, Jena and Jülich, that they have so well examined the electrochemical response of such large and complicated species. It is a mark of encouragement in terms of the vitality of the area of bioelectrochemistry that interpretation of the data obtained on these complex species has 
aroused intense controversy. The present paper is not intended to mediate such opposing interpretations and to say who is correct and who has erred. Rather, the purpose has been to review some findings on simple nucleotides and dinucleotides in the hope that consideration of such basic aspects of the methodology of using electrochemical approaches to obtain information on solution and interfacial conformation may stimulate to an even greater extent interpretation of the data on large species.

There is a general agreement that, while the electrochemical behavior patterns of polymeric nucleic acids are largely determined by the electrochemical characteristics of the component purines and pyrimidines, the structural environment in which these bases find themselves markedly affects the observed response, e.g., although faradaic reduction occurs primarily in the pyrimidine ring of the adenine and cytosine moieties, and hydrogen bonding in stranded configurations involves complementary purine-pyrimidine pairs, the ribosophosphate moieties influence not only conformation involving association, orientation and adsorption, but also electron density at electroreactive sites, whose effects may then be manifest in the current-potential patterns. Thus, detailed consideration of nucleotides of increasing complexity cannot help but facilitate understanding of the larger polynucleotides.

A possibly fruitful line of investigation involves the use of chemically modified electrodes (CME) in which a chemical compound is attached to the electrode surface by covalent bonding, irreversible adsorption or formation of a polymeric film. Attachment of nucleotides or even biopolymers to electrodes in controlled conformation may allow experiments from which energetic and kinetic information can be obtained concerning the electroactivity associated with specific orientations and states.

It must be emphasized that the electrochemical studies considered in the present paper were all made using metallic or carbon electrodes and that the situation at such metal|solution interfaces is quite different from that at membrane/solution interfaces even though electric field effects at both types of interfaces may be analogous. However, the electrochemical arrangement is the only one available for ready experimentation ; it is possible that phenomena at membrane/solution interfaces may be satisfactorily modelled electrochemically at the interface

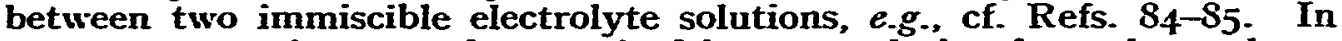
any event, caution must be exercised in extrapolating from electrochemically derived models to biological situations.

\section{Acknowledgment}

The authors thank the National Science Foundation, which helped support the work discussed. 


\section{References}

[x] B. Jaxik and P.J. Exyixg, $J$ - Am. Chems. Soc. 92 (1970) 235

[2] J.W. Webe, B. Jaxik and P.J. Elvivig, $J$ - $A$ m. Chem. Soc. 95 (1973) 99 I

[3] J.W. Webe, B. Janix and P.J. Elving, J. Am. Chem. Soc. 95 (1973) 8495

[4] T.E. Cummings, M.A. Jensen and P.J. Elvixg, Bioelectrochem. Bioenerg$4(1977)+25$

[5] V- VetTerL, Experientia 21 (1965) 9

[6] P.O.P. Ts'o, G.K. Helmkasip and C. Saxder, Proc. Natl. Acad. Sci., USA 48 (I962) 686

[7] P.O.P. TS'o and P. Lu, Proc. Natl. Arad. Sci., USA 51 (1964) I $_{7}$

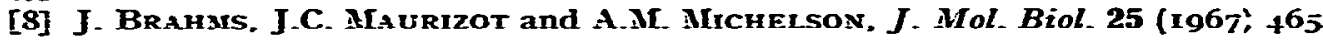

[9] S.I. Chax and I.H. Nelsox, J.Am. Chem. Soc. 91 (1969) 168

[ro] P.O.P. Ts'o, N.S. Kosdo, M.P. SchweIzer and D.P. HolkIs, Biochemistry 8 (1969) 997

[II] A.D. Broos. M.P. Schweizer and P.O.P. T'́o, J.Am. Chem. Sou. 89 $(1967) 3612$

[I2] G.K. HeLmkasip and N.S. Koxdo, Biochim. Biophys. Acta 157 (1968) 242

[13] P.O.P. Ts'o, M.F. Schweizer and D.P. Hollis, Amz. N. Y. Acad. Sai. $158(1969) 256$

[14] V. VetterL, E. מovarikova and R. Zaludova, Bioelectrockem. Bioenerg. $4(1977) 339$

[15] E. Palecek and S. Kwee, Collect. Czech. Chem. Commun. 44 (1979) 4 $^{8}$

[16] K.S.V. Sasthasay and P.J. Elvixg, J. Am. Chem. Soc. 95 (1973) 54S2

[xj] J.E. O'Reiley and P.]. Elvixg, $J$. Am. Chem. Soc. 93 (1971) 1871

[rS] K.S.V. Saxthasisl and P.J. Elvixg, $J$. Am. Chem. Soc. 96 (1974) 1653

[19] T.E. Cusisises, M.A. Jexsex and P.J. Elvixc, Bioelectrochem. Bioenerg$5(1978) 239$

[20] D. Krzassic, P. VAlextr and H.W. Nürsberg, J. Electroanal. Chem. Interfacial Electrochem. 65 (1975) $\mathrm{S6}_{3}$

[21] CPK Precision Mrolecular MLodels, The Ealing Corporation, 2225 MLassachusetts Ave., Cambridge, MLass. o2rqo, U.S.A.

[22] P. Valenta, H. W. NËrnberg and D. KrzNaric, Bioelectrochem. Bioenerg$3(1976)+18$

[23] D. Krzeiric, P. Talenta, H.U. Nürsberg and M. Braxica, J. Electroanal. Chemz. Interfacial Electrochem. 93 (197S) ir

[24] P. Valexta andi D. Krzisaric, $J$-Electroanal. Chem. Interfacial Electrochem. 75 (1977) 437

[25] Y.ME. TesIeRK and P. Valexta, J. Electroanal. Chem. Interfacial Electrochem. $93(197 \mathrm{~S}) 57$

[26] Y.M. Temerk, P. Valexta and H.W. Nürserer, J-Electroanal. Chem. Interfacial Electrochem. 100 (1979) 77

[27] D. Retter, H. Jehrivg and V. VetterL, $J$. Electroanal. Chem. Interfacial Electrockem. 57 (1974) 391

[28] V. Brabec, S.D. Christiax and G. Dryhurst, J. Electroanal. Clzem. Interfacial Electrochem. 85 ( 1977 ) 389

[29] V. Brabec, S.D. Christiax and G. Dryhurst, $J$. Electrochem. Soc. 125 (1978) 1236 
[3o] V. Brabec, M.H. Kim, S.D. Christiax and G. Drihurst, J. Electroanal. Chem. Interfacial Electrochem. 100 (1979) ro3

[3I] P. VAlexta and H.IV. Nürneterg, Biophys. Struct. Mech. 1 (197.t) I7

[32] M.A. Jensex, T.E. Cummixas and P.J. Elvixg, Bioelectrochem. Bioenerg. $4(x 977)+47$

[33] T.E. Cusisisgs and P.J. Elving, Anal. Chem. 50 (1978) 4$^{80}$

[3f] T.E. Cummings and P.J. Elvisg, Anal. Chem. 50 (1978) r9So

[35] J. Moiroux and P.J. Elvixg, Anal. Chem. 50 (1978) 1056

[36] J. Morroux and P.J. Elvisg. J. Electroanal. Chem. Interfaciul Electrochem. $102(1979) 93$

[37] Z. SANEc and P.J. Elvisg, work in progress

[38] B. Jaxik and P.J. Enving, J. Electrochem. Soc. 116 (1969) ro87

[39] C.O. Schuakel, K.S.V. Sasthasay and P.J. Elvisg, $f$. Electrochem. Soc. $121(1974) 345$

[4o] C.O. Schmakel, K.S.V. Saxthasam and P.J. Elvisg, J. Electrochem. Soc. 121 (1974) 1033

[tr] C.O. SchMaker, K.S.V. Saxthaxam and P.J. Elvixg, J. Am. Chem. Soc. $97(3975) 5_{3} 0 S_{3}$

[42] V. Vettert, J. Electroanal. Chem. Interfacial Electrochem. 19 (1968) I69

[43] V. VetTERL, Biophysik 5 (I96S) 255

[4t] M. Katz, T.E. Cuminges and P.J. Elvixg, Ber. Bunsenges. Phys. Chem. 83 (1979) 6rt

[45] P. Valesta, H.lV. Türxierg and P. Kilahre, Bioelectrochem. Bioenery$1(197+4){ }_{4} S_{7}$

[46] H.ll. Nüreberg and P. Valexta, Croat. Chem. Acta 48 (r976) 623

[47] H.II. Nürxberg. Fourth International Symposium on Bioelectrochemistry. Woods Hole, U.S.A., October 2,S, 1977

[4S] B. Malfoy, J.M. Sequaris. P. Valexta and H.W. Nürnberg, Bioelectrochem. Bioenerg. 3 (1976) $44^{\circ}$

[49] J.MI. Sequaris, B. MLalfoy, P. Valesta and H.ll. Nürneerg, Bioelectrochem. Bioenerg. 3 (1974) +6r

[5o] B. Malfor. J.M. Sequaris, P. Valexta and H.lW. Nürserg, $J$. Elegtroanal. Chem. Interfacial Electrochem. 75 (1977) $\mathbf{4 5}$

[51] H.W. Nürsierg and P. Valexta, Proc. 29 Colston Symp., Bristol 1977, Scientechnica, Bristol, 1978, pp. 201-229, 23+-236

[52] J.Mr. Seguaris, P. Valesta. H. W. Nürsberg and B. Mlalfox, Proc. 29 Colston Symp. Bristol 1977. Scientechnica, Bristol, 1978, pp. 230-234

[53] E. Palecek and V. VetTerl, Biopolymers 6 (1968) 9 I7

[5+] E. Palecek, J. Electroanal. Chem. Interfacial Electrochem. 22 (1969) 3+7

[55] V. Brabec and E. Palecek, Biophysik 6 (1970) 290

[56] E. Palecek, Collect. Czech. Chem. Commun. 39 (1974) 3449

[57] V. Brabec and E. Palecek, Biophys. Chem. 4 (r976) 79

[58] T. YaMane and N. Davidsox, J. Am. Chem. Soc. 83 (196I) 2599

[59] U.S. Nandi, J.C. WaNg and N. Davidsox, Biochemistry 4 (1965) 1687

[6o] MI.N. Williass and D.M. Crothers, Biochemistry 14 (1975) 1944

[61] A. Walter and G. Luch, Nucleic Acids Res., 4 (3) (1977) 539

[62] G. Albiser and S. Prenilat, C. R. Hebd. Seances Acad. Sui. Ser. D 282 (1976) 1557 
[63] H. BeRG, Bíolectrochem. Bioenerg. 4 (1977) 522

[64] H. Berg, G. Horn and J. Flemming. Proceedings, Biophysical Congress, Kyoto, $197 \mathrm{~S}$, Kobatake, 1979, in press

[65] H. Berg, Reo. Polarogr. 24 (1979) 121

[66] E. Palncek, Proceedings of the Conference on Electroanalysis in Hygiene, Entironmental, Clinical and Pharmaceutical Chemistry, UV.F. SuxTH (Editor), Elsevier, London. 1979, in press

[67] V. Brabec and E. Palecek, J. Electroanal. Chem. Interfacial Electrochem. $88(1978) 373$

[68] B. MIAfoy and J.A. ReYxiud, J. Electroanal. Chem. Interfacial Electrochen. 67 (1976) 359

[69] J.A. Reynaud, B. Mlalfoy, J.M. Sequaris and P.J. Sicard, Bioelectrochem. Bioenerg. 4 (1977) 380

[70] V. Brabec and E. Palecek, Biopolymers 11 (1972) 2577

[jI] R.D. Brave, K.S.V. Santhanait and P.J. Elvivg, J. Am. Chem. Soc. 97 (1975) 2591

[T2] P.J. Elving, C.O. Schuaker and K.S.V. Santhavas, Crit. Rev. Anal. Chems. $6(1976)$ I

[73] R.H. Sarya and R.J. Mysort, $J$. Am. Chem. Soc. 95 (1973) 7470

[74] W.D. Hasiml., R.J- Pugmire and D.M. Graxt, J. Am. Chem. Sog. 96 (197+) $28 S_{5}$

[75] D. Perahix, B. Pulgyax and A. Sarax, in Structure and Conformation of Nrcleic Acids and Protein-Nucleic Acid Interactions, M. Sundaralingar and S.T. RAo (Editors), University Park Press, Baltimore (1975) p. 685

[76] C.O. Schinkex, M.A. Jexsex and P.J. Elvisc, Bioelectrochem. Bioererg$5(1978) 625$

[77] E.J. Laxd and A.J. Swaleow, Biochim. Biophys. Acta 162 (1968) 162

[78] J- Mlorkoux and P.J. Elvixg, Anal. Chem. 346 (r979) 5 T

[79] W.T. Bressihax and P.J. Elvixg, work in progress

[80] H. Kixoshita, S.D. Christias, M.H. Kis, J.G. Baker and G. Dryhurst, in Electrochemical Studies of Biological Syrstems, D.T. SAwyer (Editor), A.C.S. Symposium Series 38, American Chemical Society, 1977, p. 128

[81] P.O.P. Ts'o, J.S. Melvix and A.C. Orson, J. Am. Chem. Soc. 85 (1963) r289

[82] J. Doxonue, Arch. Biochem. Biophys. 128 (1968) $59 x$

[83] P.J. Elv1:ig, Topics in Bioelectrochenistry and Bioenergetics, G. Mrcazzo (Editor), John Wiley and Sons, London (1976) Vol. I, p. 180-286

[84] Z. Snsiec, $J$. Electroanal. Chem. Interfacial Electrochem. 99 (1979) 197

[85] Z. Sashec, V. MARecek, J. VEeber and D. Hoyolka, J. Electroanal. Chem. Interfasial Electrochem. 99 (1979) $3_{5}$ 